\title{
Erratum to: Information System Concepts
}

Eckhard D. Falkenberg ${ }^{1}$, Kalle Lyytinen ${ }^{2}$, and Alexander A. Verrijn-Stuart ${ }^{3}$

1 Germany

2 University of Jyväskylä, Finland

3 University of Leiden, The Netherlands

\section{Erratum to:}

\section{E.D. Falkenberg et al. (Eds.)}

Information System Concepts

DOI: $10.1007 / 978-0-387-35500-9$

The book was inadvertently published with an incorrect name of the copyright holder. The name of the copyright holder for this book is: (c) IFIP International Federation for Information Processing. The book has been updated with the changes. 